\title{
METHODS OF IMAGING IN THE DIAGNOSIS OF TEMPOROMANDIBULAR JOINT DISORDERS
}

\author{
Petr Tvrdy
}

Department of Oral and Maxillofacial Surgery, Faculty of Medicine and Dentistry, Palacký University, I. P. Pavlova 6, 77520 Olomouc, Czech republic

e-mail:tvrdyp@fnol.cz

Received: September 5, 2006; Accepted: January 21, 2007

Key words: Temporomandibular joint/Methods of imaging/Examinations

Background: Different methods of temporomandibular joint imaging are presented and discussed. Research reports published from 1979 to 2002 have been evaluated.

Method and Results: The aim of this paper is to summarize the main findings from research. Basic X-ray examination is the most readily available method of imaging which usually does not have any contraindication. The use of computer tomography offers all advantages of tomographic scanning in different layers and projections, imaging soft tissues close to the joint and the possibility of "3D" reconstruction of bone structures. In case of joint dysfunctions and internal joint derangement, it is more preferable to use nuclear magnetic resonance for the depiction of the joint structures.

To make a diagnosis more efficient, miniinvasive diagnostic methods are becoming necessary. Arthroscopy allows direct visual control of the joint space with the possibility of therapeutic help in cases when conservative treatment has failed. Ultrasonography, as a completely non-invasive procedure, is applied even in diagnosing functional temporomandibular defects. In these cases the diagnostic value of ultrasonography is almost comparable with this of nuclear magnetic resonance.

Conclusions: So it is possible that, together with the improvement of the equipment, development of the diagnostic methods used during the treatment of temporomandibular joint defects could continue in this direction.

\section{INTRODUCTION}

Temporomandibular joint (TMJ) disorders (TMD) constitute a number of functional and pathological changes affecting not only the TMJ, but also the masticatory muscles (and eventually all other parts of the stomathognate system). The number of affected people also is increasing, perhaps due to the influence of mental tension in today's society. Temporomandibular disorders have a multifactorial pathogenic background and very miscellaneous clinical symptoms. According to an earlier psychophysiological concept, occlusion and emotional stress were considered to be the most serious etiological factors. The causes of TMD are perhaps much more complicated. The correct diagnosis of TMJ dysfunctions cannot be based on clinical examination only. Nowadays, in clinical practice, we cannot dispense with the methods of imaging ${ }^{1,2}$. Among the basic examinations used are: Xray examination (RTG), computer tomography (CT) and magnetic resonance imaging (MRI). Radionuclide examination (scintigraphy), ultrasonography and arthroscopy are less used, secondary methods of imaging. Arthroscopy is classed as a therapeutic method ${ }^{25}$.

\section{RADIODIAGNOSTIC EXAMINATION}

The importance of X-ray examination in diagnosing TMD is still a matter of debate. Until recently, use the standard, mostly lateral and oblique imaging was the main reason for doubt as summation of the joint structures with the surrounding tissues ${ }^{11,15}$. Other authors based their conclusions on clinical observations, which in many cases was unavoidable considerable disagreement between the clinical manifestation and the X-ray picture ${ }^{6}$. In spite of these doubts, $\mathrm{X}$-ray examination is still necessary and thanks to technical progress, especially in panoramic projection, it assists in making the right diagnosis. In particular, this applies to diagnosis of TMJ traumatic disorders. To see the configuration of the joint structures correctly, at least in two different views perpendicular projections are necessary. In clinical practice the lateral view is the most common. This best shows positional, structural and functional changes. The advantage of coronary tomography is presentation of both TMJ at the same time.

X-ray methods can be divided into transfacial, transcranial and subcranial. Lateral (Parma's) view belongs to transfacial tomography, prohibited by hygienic regulations owing to the high level of skin radiation dose. Its modification is Albers-Schönberg projection. The picture is taken 
with the mouth open and with the X-ray tube in place. In another, so-called Porders's projection, the ray is directed through an mandibular incisure of the reverse side of the mandible. The oblique Schüller's view is the most common transcranial projection. The ray is directed from a point about $10 \mathrm{~cm}$ above the TMJ focused down on the examined joint. Subcranial tomography mostly uses the Clementschitsch view of the skull with the mouth open. However, the morphological changes of bone structures can be blurred by the surrounding bone structures ${ }^{6,18}$.

PANORAMIC RADIOGRAPHY is a very good method of imaging both TMJ and other jaw and tooth structures. The modern orthopantomography offers a wider range of projection. The projection of both joints with the mouth opened or closed in one film is convenient for the diagnosis of TMK disorders. It is an alternative method for X-ray examination of condylar fractures ${ }^{12}$.

ARTHROGRAPHY has been, until the adoption of computer tomography (CT) and magnetic resonance, the only technique provide information on the condition of the cartilage and the joint disc. The arthographic technique was already described in the 1940s, but it was not introduced into clinical practice until the end of the $1970 \mathrm{~s}^{1}$. There are two methods of implementation: contrast substance is injected into the upper joint space (above the joint disc), less often into the lower, or both spaces. In double-contrast arthography, a small amount of air is introduced after application of the contrast-substance. However, comparative studies have not proved any statistically important difference in the accuracy of the two methods of projection. Single-contrast arthography has been used more often. The use of the contrast substance is most frequently completed by Schuller tomography scanning. The filled joint can be scanned to eliminate the disruptive influence of the surrounding tissues.

When magnetic resonance is not available, arthrography is the most accurate method of confirming anterior dislocation of the joint disc. Its accuracy is $84-100 \%$. Articular disc perforations and intrarticular adhesions are accurately identified by this technique ${ }^{1,7,11,14}$.

\section{COMPUTER TOMOGRAPHY (CT)}

The use of CT in diagnosing TMJ disorders dates back to the late 1980s. Huls et al (supported by Siemens) have collected the most comprehensive case studies of patients with TMJ examined by CT. CT is very often used in diagnosing disc dislocation, condylar fractures, degenerative bone changes and ankylosis.

Arthrography is combined with computer tomography, which enhances the accuracy of the diagnosis of internal TMJ disorders. The first studies showed, in comparison with the surgical findings, that the disc dislocations represent about $81 \%$ of the total number of TMD (later and more extensive studies proved only $66 \%$ ). The same result was proved also by the studies of degenerative bone changes. It was also found that CT failed to reveal smaller disc perforations. In the most recent studies CT was evaluated as a good method, but less convenient than magnetic resonance $6,7,9,10,19$.

\section{MAGNETIC RESONANCE IMAGING (MRI)}

Magnetic resonance is an imaging method of high resolution efficiency having no undesirable side effects. During the examination the body is placed in a strong magnetic field which causes hydrogen proton dipoles to align parallel to the magnetic field lines. Added radiofrequential pulses of set defined frequency provoke the resonance of extra and intracellular hydrogen ions. After the radiofrequency pulse is stopped, the so-called relaxing phase sets in. During this phase atomic nuclei irradiate radio waves recorded by the equipment. Different tissues produce different quantities of energy. Regional relaxing time calculations serve as the picture reconstruction at any atomic level. In the 1980s MRI was used for the first time introducing the so-called surface spool for examination and featuring of TMJ structures.

Compared with arthrography and CT pictures, MRI is more correct when featuring degenerative bone changes (60-100 \%) and disc dislocation (73-95\%). Synovial and subsynovial tissues can be viewed as well. Many studies have demonstrated MRI to be the best method of displaying TMJ hard and soft tissues. With the help of MRI, it is possible to detect pathological changes of the chewing muscles. However, no connection has been shown between these changes shown by MRI and the clinical symptoms of the TMJ defect ${ }^{2,14,16,17,18,20 .}$

\section{RADIONUCLIDE EXAMINATION}

Scintigraphy aids to discover early changes in the TMJ skeleton which may also result in joint disc abnormalities. Radionuclide $99 m T c$ is used for the examination. The temporomandibular joint is ideal for what is called SPECT (single proton emission computed tomography), because it is a quite small joint situated close to the skull base and paranasal sinuses. So SPECT can, unlike the double-dimension featuring, present TMJ separately from the parts of high bone density. The radionuclide examination sensitivity is high, its specificity is however low. Any inflammation, trauma or tumors increase the local isotope concentration. For this reason many studies state that radionuclide examination is relevant only as a screening $\operatorname{method}^{21,22}$.

\section{ULTRASONOGRAPHY}

TMJ ultrasonography is a non-invasive, readily available and relatively cheap dynamic "real time" examination, featuring soft joint tissues. It serves both for diagnosis and differential diagnosis and for the comparison of therapeutic results in treating internal joint defects. The first reports of TMJ sonography date back to 2000 It uses currently available types of utrasonic equipment with a linear scanning transducer of 7.5-12 MHz frequency, which makes it possible to depict the narrow space of the jaw joint and the position of the joint disc and it reveals fluid or ligament adhesion. During the examination the patient is in the sitting position and the transducer is placed on the skin above the joint parallel to the long axis of the mandible branch. The joint disc is scanned on the screen as a thin homogen hypo, as far as the isoechogen strip contiguous to the condyle border. The condyle bone 
borders and articular eminence show as a hyperechogen line. During the examination it is possible to directly observe the joint disc move when the mouth is opening and closing. Studies comparing the results of MRI and sonography showed 70-85\% agreement. An ultrasonographic system using the high frequency and conveyors with a largediameter has been recently invented. The ultrasonograph waves, generated by this system, are able to penetrate easily through the small aperture between the glenoid fossa and the condyl. This new ring transducer has a high focus depth and narrow wave beam. The bone surface rebounds as much as $2 / 3$ of the waves, only $1 / 3$ propagating down to deeper structures. For this reason the transmitter must be placed on a specific place, with the aim to transmit waves through the soft tissues, situated between the condyle and the eminence ${ }^{3,4,5,17}$.

\section{ARTHROSCOPY}

Arthroscopy is both a therapeutic and miniinvasive endoscopic method for TMJ space examination. TMJ arthroscopy was first described in the 1970s (Ohnishi). It facilitates joint space visual control, supplying information about the joint disc position, the synovia, joint cartilage and about the presence of adhesions. It is used in diagnosing and treating internal TMJ derangement, TMJ degenerative disorders, synovitis, TMJ hypo and hypermobility. It is performed under general anesthesia with percutaneously installed trocars and an optical probe of 1.9-2.4 mm diameter. The intraarticular picture is transmitted by a light cable onto the screen. However, complications may arise such as haemorrhage, joint cartilage damage, joint disc perforation, face inervation damage, midear perforation, intracranial perforations and the risk of infection ${ }^{8,13}$.

\section{CONCLUSION}

Reliable case history and the patient's clinical examination are usually insufficient to base exact diagnosis of temporomandibular defects on. In practice, it is the type of the method of depiction that matters in assesing the diagnosis and in choosing the best way of treatment.. Basic X-ray examination is the most readily available method of imaging which usually has no contraindications. A good quality X-ray image allows us to confirm or to exclude possible traumatic damage of the joint bone structures. An orthopantomogram within the framework of the "joint program" helps us to discover small bone defects or pathological positions of the joint condyles. Its drawbacks are limited resolution power and failure in identifying the soft structures. This disadvantage can be eliminated by arthography which in some cases replaces MR examination. However, the arthography is an invasive examination and is accompanied by the risk of allergic reaction connected with contrast substance application. For it to be successful if calls for a specialist with some experience. The use of computer tomography offers all advantages of tomographic scanning in different layers and projections. The possibility of imaging soft tissues close to the joint and the possibility of "3D" reconstruction of bone structures are a great advantage. Nevertheless, the results can be compromised by artifacts due to the presence of metallic structures inside the oral cavity (amalgam fillings, metallic dentures) and not totally clear featuring of the joint disc shape and position. That is why in case of joint dysfunctions and internal joint derangement, it is preferable to use nuclear magnetic resonance for the depiction of the joint structures. Even if this it is not a routine examination method, it is indispensable before planning a surgical procedure of the soft joint structures. The examination requires good co-operation with the patients. They must remain still during the measurement. The examination is quite long (about $45 \mathrm{~min}$ ), very expensive and not always available. To make a diagnosis more efficient, new miniinvasive diagnostic methods are becoming necessary. Arthroscopy allows direct visual control of the joint aperture with the possibility of therapeutic help in cases when conservative treatment has failed. In contrast with the "open" operation methods, it is involves a smaller risk of complications during the surgery. High financial expenses (arthroscopy devices and accessories costs) and the necessity of general anaesthesia make this method available in specialized departments only. For this reason this method cannot be classified as a routine examination. Ultrasonography, as a completely non-invasive procedure, commonly used in many branches of medicine and applied even in diagnosing functional temporomandibular defects. Its great advantage mainly consists in the possibility of depicting dynamic joint structures, particularly the condyle line and the joint disc position. In these cases the diagnostic value of sonography almost equals the diagnostic importance of nuclear magnetic resonance.

Along with improvements in equipment and development of diagnostic methods used during the treatment of temporomandibular joint defects progress is expected in the current direction.

\section{REFERENCES}

1. Westesson PL, Bronstein SL: Temporomandibular joint: comparison of single- and double-contrast arthrography. Radiology 1987; 164:65-70

2. Tasaki MM, Westesson PL: Temporomandibular joint: diagnostic accuracy with sagittal and coronal MR imaging. Radiology 1993; 186:723-729.

3. Stefanoff V, Hausamen JE, van den Berghe P: Ultrasound imaging of the TMJ disk in asymptomatic volunteers: preliminary report. J Craniomaxillofac Surg 1992; 20:337-340.

4. Emshoff R, Bertram S, Rudisch A, Gaßner R. The diagnostic value of ultrasonography to determine the temporomandibular disk position. Oral Surg Oral Med Oral Pathol Oral Radiol Endod 1997; 84:688-696.

5. Emshoff R, Rudisch A. Validity of clinical diagnostic criteria for temporomandibular disorders: clinical versus magnetic resonance imaging diagnosis of temporomandibular joint internal derangement and osteoarthrosis. Oral Surg Oral Med Oral Pathol Oral Radiol Endod 2001; 91:50-55.

6. Katzberg RW. Temporomandibular joint imaging. Radiology 1989; 170:297-307.

7. Brooks SL, Brand JW, Gibbs SJ, et al. Imaging of the temporomandibular joint. A position paper of the American Academy of Oral 
and Maxillofacial Radiology. Oral Surg Oral Med Oral Pathol Oral Radiol Endod 1997; 83:609-618.

8. Murakami K, Ito K. Arthroscopy of the temporomandibular joint. In: Watanabe M, eds. Arthroscopy of small joints. Tokyo, Japan: Igaku-Shoin 1985; 128-139.

9. Helms AC, Kaplan P. Diagnostic imaging of the temporomandibular joint: recommendations for use of the various techniques. AJR Am J Roentgenol 1990; 154:319-322

10. Kotráň M. a kol..: Diagnostika lézií temporomandibulárního kíbu pomocou počitačovej tomografie. Čes. Stomat... 1994; 94(4):181190.

11. Kotráň M. a kol.: Etiológia, diagnostika a terapia ochorení temporomandibulárního kíbu. Vysokoškolské učebné texty , Univerzita P. J. Šafárika Košice 1984; p. 130.

12. Dahlström L, Lindvall AM. Assessment of temporomandibular joint disease by parnoramic radiography: reliability and validity in relation to tomography. Dentomaxillofac Radiol 1996; 25:197201.

13. McCain JP. Arthroscopy of the human temporomandibular joint. J Oral Maxillofac. Surg 1988; 46:648-655.

14. Kaplan PA, Tu HK, Williams SM, et al. The normal temporomandibular joint: MR and arthrographic correlation. Radiology 1987; 165:177-178.

15. Solberg WK, Woo MW, Houston JB. Prevalence of mandibular dysfunction in young adults. J Am Dent Assoc 1979; 98:25-34.
16. Terheyden H, Fleiner B, Schubert F, et al. Zur position des discus bei collum-mandibulae frakturen: eine magnetresonanztomographische studie. In: Suchardt K, Schwenzer N, eds. Fortschritte der kiefer- und gesichts-chirurgie, ein jahrbuch.; Bd 41.

17. Hayashi T, Ito J, Koyama J, et al. The accuracy of sonography for evaluation of internal derangement of the temporomandibular joint in asymptomatic elementary school children: comparison with MR and CT. AJNR Am J Neuroradiol 2001; 22:728-734.

18. Murphy WA, Kaplan PA. Temporomandibular joint. In: Resnick D, eds. Diagnosis of bone and joint disorders. Saunders 1995; 1699-1754.

19. Katzberg RW, Westesson PL, Tallents RH, Drake CM. Anatomic disorders of the temporomandibular joint disc in asymptomatic subjects. J Oral Maxillofac Surg 1996; 54:147-153.

20. Held P, Moritz M, Fellner C, et al. Magnetic resonance of the disk of the temporomandibular joint: MR imaging protocol. Clin Imaging 1996; 20:204-211.

21. Nuebler-Moritz M, Marienhagen J, Held P, et al: High-resolution SPECT of the temporomandibular joint in chronic craniofacial pain disorders: a pilot study. Acta Stomatol Belg 1995 Sep; 92(3):125-8.

22. Oesterreich FU, Jend-Rossmann I, Jend HH, Triebel HJ: Semiquantitative SPECT imaging for assessment of bone reactions in internal derangements of the temporomandibular joint. J Oral Maxillofac Surg 1987 Dec; 45(12):1022-8. 